\title{
Jorge Valentim - “Corpo no outro corpo": homoerotismo na narrativa portuguesa contemporânea
}

São Carlos: Edufscar, 2016

Maria Lúcia Outeiro Fernandes

Os estudos sobre gênero na literatura ganham eminente contribuição com o lançamento do livro "Corpo no outro corpo": homoerotismo na narrativa portuguesa contemporânea, de Jorge Vicente Valentim, publicado em 2016 pela Editora da Universidade Federal de São Carlos (ufscar). Nos dois primeiros capítulos, o autor empreende uma revisão da literatura que aborda questões relacionadas à homoeroticidade. Nesse percurso, busca situar o leitor criando um horizonte de expectativas configurado tanto por obras literárias quanto por obras críticas, que, de alguma maneira, abordam aspectos relativos ao universo que se propõe a analisar.

Essa preocupação em mapear os trabalhos já desenvolvidos insere a obra numa rede de trabalhos conexos e colabora para conferir uma identidade a seu próprio texto, apontando o lugar que deverá ocupar. Isto porque, à medida que vai descrevendo a contribuição de cada autor, Valentim vai delineando sua própria metodologia de trabalho, seus objetivos e sua posição crítica em relação ao objeto de sua pesquisa de pós-doutorado, desenvolvida na Universidade do Porto, durante o ano de 2013, sob a supervisão de Isabel Pires de Lima, que assina o prefácio do livro que dela resultou.

Nessa demarcação, Jorge Valentim deixa claro que pretende estabelecer uma associação entre as questões relacionadas à homossexualidade e outras, trazidas pelas teorias da pós-modernidade. Ademais, o autor também busca definir uma especificidade em relação à abordagem do tema, no âmbito da literatura portuguesa e do contexto em que emergem essas questões. Daí recorrer, na fundamentação teórico-crítica, às obras de autores que se tornaram obrigatórias em qualquer estudo sobre a literatura portuguesa das últimas décadas do século $\mathrm{xx}$ até hoje, entre os quais se destacam: Eduardo

Doutora em Letras e professora da Universidade Estadual Paulista (Unesp), Araraquara, sP, Brasil. E-mail: outeiro@fclar.unesp.br 
Prado Coelho, Maria Alzira Seixo, Carlos Ceia, Isabel Pires Lima, João Barrento, Ana Paula Arnaut e Carlos Reis, além de Boaventura de Sousa Santos. Desse modo, o livro não constitui mero levantamento de obras que adotam temas relacionados à homossexualidade, mas constitui um trabalho de interpretação destes temas, pela perspectiva de questionamentos trazidos por teorias contemporâneas acerca da natureza e da função da arte, bem como de suas características e fundamentos críticos.

Como ponto de partida para tal associação, o autor vale-se de algumas reflexões desenvolvidas por Ítalo Moriconi (2002), que o auxiliam a compreender de que modo, na literatura contemporânea, as abordagens sobre a homossexualidade estão quase sempre associadas aos propósitos de desmascaramento das homofobias de todos os matizes, tendo por principal objetivo levar os leitores a refletirem acerca das novas formações identitárias. Nessa perspectiva, um dos aspectos mais relevantes dessa produção literária é a relação que viabiliza entre uma teoria da identidade gay e as questões relacionadas ao estatuto do sujeito na condição pós-moderna, resumida muitas vezes na tão propalada "morte do sujeito" (HALl, 2002). Na verdade, quem estuda literatura contemporânea pelo viés das teorias da pós-modernidade não fala exatamente em morte do sujeito, mas numa consciência de que o sujeito também tem uma natureza de construto. Para esses autores, a noção de sujeito autônomo, tal como configurado nas obras realistas, não pode estar separada de um conceito de sujeito construído como se fosse uma essência. Muitas teorias da pós-modernidade apontam para uma desconstrução dessa noção essencialista de sujeito demonstrando o caráter de construção cultural dos sujeitos e das identidades. Desse modo ressaltam a fragilidade do conceito romântico e realista de sujeito, apontando, ao contrário, para o seu caráter provisório, em constante mutação, além de sua relação intrínseca com uma comunidade ou uma classe em que esteja inserido.

Coerente com as perspectivas pós-modernas, Valentim empreende uma articulação eficiente entre as abordagens contemporâneas das questões homoafetivas e as reflexões acerca da identidade como construção histórica e cultural das subjetividades. É por meio deste viés crítico que aborda, no segundo capítulo, as obras pioneiras na focalização da temática homoerótica na prosa ficcional, tais como: Sedução (1937), de José Marmelo e Silva; Mau tempo no canal (1944), de Vitorino Nemésio; Internato (1946), de João Gaspar Simões; O pecado de foão Agonia (1961), de Bernardo Santareno; O libertino passeia por 
Braga, a idolátrica, o seu esplendor (escrito em 1961 e publicado em 1970), de Luís Pacheco; O físico prodigioso (1966), Os grão-capitães (1971) e Sinais de Fogo (1979), de Jorge de Sena; e O perdão da puberdade (1974), de Perry Nava (Luís Miguel Nava). É pelo mesmo viés crítico que aborda, na segunda da seção deste capítulo, as obras publicadas no cenário pós-25 de Abril, marcado de início pela publicação da revista Gaiola Aberta (de 1974 a 1983, na primeira série, e de 2003 a 2006, na segunda série). Nessa seção, Valentim descreve a formação de um cenário que prepara o aparecimento da obra de Guilherme de Melo, caracterizada no capítulo seguinte como a primeira obra que ousa dar visibilidade ao homoerotismo:

há um certo consenso em perceber neste escritor o momento em que não só a temática homoerótica fincava seus pés definitivamente na ficção portuguesa contemporânea, mas também em que a autoria homossexual saía do armário [...] e assumia uma postura ativista de presença e de intervenção em favor dos direitos da comunidade (VAlEnTiM, 2016, p. 109).

Além da questão do sujeito, outro aspecto selecionado por Jorge Valentim das teorias acerca da literatura pós-moderna é a noção de metafição historiográfica, evocada por ele em vários momentos de suas análises. Sente-se falta, porém, de uma reflexão mais acurada para o uso desta categoria como instrumento de análise das obras abordadas. O texto metaficcional implica uma fuga à mimese, à representação do real nos moldes da estética românticorealista. A categoria da metafição historiográfica, proposta por Linda Hutcheon (1980; 1991) aplica-se a um tipo de texto que contesta o estilo realista de narrativa, ao mesmo tempo que reflete acerca dos mecanismos de sua produção. Em vez de propor um texto que finge (ficcionaliza) uma realidade, como se fosse a representação perfeita de uma verdade autônoma, externa ao texto, o escritor propõe uma narrativa que olha para a sua própria realidade, ou seja, coloca em cena os mecanismos de sua construção, ressaltando os efeitos desses mecanismos na própria elaboração do que se entende como real.

Seria interessante, nessa linha de raciocínio, ampliar e problematizar um pouco o conceito proposto por Hutcheon, porque, de fato, as narrativas que tratam das identidades homoafetivas em geral não tratam exatamente de fatos históricos, como ocorre nas metafições historiográficas estudadas pela pesquisadora canadense. Embora as questões vivenciadas pelas comunidades gays possam ser tomadas como fatos históricos, é necessário pontuar a especificidade encontrada nessas obras. De fato os procedimentos são muito 
semelhantes. Estamos diante de narrativas que abordam fatos relacionadas ao universo gay, mas não se trata exatamente de fatos históricos e sim de discursos sobre identidades sexuais. Então, os elementos narrativos mobilizados não são aqueles adotados em narrativas históricas, mas em narrativas do eu, principalmente autobiografias e livros de memória.

Trata-se, portanto, de uma apropriação de escritas do eu que, ao mesmo tempo que analisam aspectos relacionados a uma vivência contemporânea dos gays na vida real, no contexto histórico, também empreendem uma complexa reflexão acerca de sua própria especificidade e, principalmente, dos discursos que dominam esse contexto e que têm por principal objetivo perpetuar a ideia de uma heteronormatividade. Esses discursos, em geral, são colocados nessas obras metaficcionais ao lado de outros discursos desconstrutores da visão tradicional das sexualidades humanas, trazendo à tona a luta pela emancipação de novas formas de entender as identidades humanas no que tange a seu comportamento sexual.

Pode-se pensar de modo especial nas obras de Silviano Santiago, que constituem modelos dessa espécie de "metafição autobiográfica". Tal como ocorre na conceituação de Linda Hutcheon, os escritores se apossam de inúmeros elementos das diversas formas de escrita do eu, mas seus objetivos ultrapassam o desejo de apenas contar uma história desses sujeitos, para se estabelecerem como narrativas que apresentam uma reflexão sobre as formas de narrar os fatos vivenciados por esses protagonistas.

Um trabalho exemplar para se pensar esse modelo é o romance de Silviano Santiago, O falso mentiroso (2004). O narrador, Samuel Carneiro de Souza Aguiar, coloca-se como um mentiroso, não porque esteja enganando o leitor o tempo todo, mas porque vai possibilitar ao leitor entender que sua narrativa não passa de um jogo, montado por um "louco", ou seja, por alguém que se permite extrapolar as regras e os pactos da narrativa autobiográfica (da mesma forma que poderia extrapolar as regras da narrativa histórica, no caso de uma narrativa que trabalhasse com fatos históricos). Paradoxalmente, por essa forma de conceber a narrativa literária, como jogo de linguagem e não como representação de um real externo, o narrador não pode ser interpretado como "mentiroso". Embora haja referências ao contexto histórico, o que predomina no livro de Santiago é a abordagem de uma narrativa do eu - uma narrativa que questiona o estabelecimento de uma verdade do sujeito e não uma verdade de um fato histórico. 
Mais que a abordagem da temática, Valentim enfatiza nas análises que empreende os modos específicos como os autores tentam realizar uma literatura homoerótica, desfazendo identidades consideradas como essências imutáveis. As minorias gay não são abordadas exclusivamente do ponto de vista do contexto - a situação efetiva destes grupos na sociedade contemporânea -, mas de maneira a realçar o modo como a literatura pós-moderna adota uma postura crítica em relação aos discursos da sociedade eurocêntrica e patriarcal, que impõem a heteronormatividade. A homoafetividade é abordada sobretudo como elemento de crítica social e política. Acima de tudo, a grande contribuição do estudo de Jorge Valentim é a análise que empreende dos múltiplos discursos que surgem no contexto lusitano acerca da homoafetividade, tanto no âmbito da crítica quanto da produção literária.

Embora não aprofunde as questões teóricas, optando por deter-se na análise das obras em si, a interpretação que Valentim faz delas aponta para a complexidade do campo minado por diversas teorias lutando por espaços de legitimação que implicam posicionamentos políticos diversos e polêmicos ao tratarem das representações da identidade. Sutilmente, pontua as diferenças que norteiam a escolha dos termos, que remetem a uma profusão de campos teóricos. Sabiamente opta pelo termo homoerotismo, que engloba os principais aspectos analisados sem se comprometer com os dois lados radicais na abordagem dessas questões: de um lado as ideias pregadas pelos Gays Studies, em busca de uma normalização alternativa da sexualidade; e, de outro, a Teoria Queer, que enfatiza a condição múltipla e cambiante das identidades homoafetivas.

O terceiro capítulo, que constitui a maior parte e o cerne do livro, é todo dedicado à obra de Guilherme de Melo. Na minuciosa e pertinente abordagem analítica, Valentim não se limita à análise das questões homoeróticas, mas intenta uma compreensão acerca da invisibilidade em que a obra de Melo é mantida pela crítica literária lusitana, buscando encontrar as causas de sua ausência no cânone literário.

A seguir, Valentim contrapõe à indiferença da crítica pelas questões relacionadas à homossexualidade na literatura, os textos radicalmente lúcidos e combativos de Natália Correia, que coloca o dedo fundo na ferida do preconceito que permeia a história da literatura, tanto quanto a história da sociedade portuguesa. Além de estabelecer as devidas conexões, conscientes 
ou não, entre estes textos e os do grande teórico da sexualidade, Michel Foucault, ressaltando o pioneirismo das abordagens da autora portuguesa no cenário nacional, a análise de Jorge Valentim tem o grande mérito de adotar uma perspectiva crítica já empreendida no seio da intelectualidade portuguesa acerca das questões homoeróticas. Longe de desdenhar desse veio crítico já existente, Valentim o retoma, ressaltando a colaboração mais recente de críticos como Eduardo Pitta, Lucia Facco, Miguel Real, Mário César Lugarinho e nele se inserindo com propriedade.

Do ponto de vista metodológico, seria interessante destacar também o acerto do pesquisador na análise das obras literárias, ao recorrer a outro instrumental teórico-metodológico relevante, que é a proposta de Antonio Candido de investigar fatos exteriores ao texto - no caso, os fatos relacionados à vivência de personagens gays -, sempre associados aos mecanismos de narrativa adotados pelos autores estudados.

Essa estratégia de abordagem torna-se ainda mais explícita no último capítulo, na análise que empreende da obra de Mário Cláudio, que parte dos procedimentos narrativos pautados por duas características, a visibilidade e a multiplicidade, duas das seis propostas de Ítalo Calvino (2006) para a literatura típica do século XXI. É de se notar que o escritor italiano foi um dos principais autores que influenciaram no surgimento das teorias sobre a pós-modernidade.

Desse modo, fecha-se o percurso de Jorge Valentim nessa busca por uma leitura do homoerotismo na literatura portuguesa de maneira articulada com questões trazidas pelas perspectivas pós-modernas, o que confere às obras analisadas um relevante papel na crítica às representações da sexualidade humana. Valentim aponta o modo como essas obras desconstroem as estratégias sociais normalizadoras, que estabelecem sujeitos sexuais estáveis, ao colocarem em cena identidades contaminadas pela ideia de "devir", que caracterizam os modos alternativos, dissidentes, contraculturais de subjetivação. As análises, principalmente das narrativas de Guilherme de Melo e Mário Cláudio, apontam para a instabilidade da ordem, ao concorrerem para o rompimento de lógicas binárias, resultantes do estabelecimento de hierarquias e dos jogos de poder.

Enfim, o trabalho de Jorge Valentim concorre para se entender a literatura dentro da perspectiva ressaltada por J. C. Barcellos (2006, p. 45):

A literatura explora criticamente as diferentes textualizações culturais que, em si, já são interpretações da realidade e o faz precisamente através daquilo que 
a constitui como literatura, a saber, o intenso trabalho formal de desfamiliarização da linguagem [...]. A obra literária é necessariamente uma interpretação crítica das textualizações da cultura"

Para concluir esta resenha, parece pertinente citar outra pesquisadora, que também se manifesta sobre a relevância das teorias da pós-modernidade para os estudos de gênero, Heloísa Buarque de Hollanda. Segundo a pesquisadora, os estudos de gênero foram bastante enriquecidos com as reflexões acerca da pós-modernidade, que contribuíram para a configuração de uma "utopia do dissenso", termo que se refere à busca de uma convivência das diferenças ou à esperança no advento de uma democracia radical, na qual conviveriam todas as diferenças, objeto de reflexão de vários teóricos da pós-modernidade, entre os quais Ernesto Laclau (1992).

Nas últimas décadas, porém, não foi isso que se verificou. Assim que surgiram os múltiplos movimentos de reivindicações de direitos das minorias, houve o recrudescimento de uma onda de conservadorismo em todos os setores da sociedade ocidental e em todas as áreas do conhecimento. E o resultado foi uma avalanche de manifestações de intolerância ideológica, religiosa e política, que se reflete também na intolerância a comportamentos vistos como abusivos e não naturais.

Têm tido lugar algumas das mais insensatas propostas de políticas que visam deter os movimentos de emancipação de grupos minoritários surgidos a partir dos anos 1970 e 1980 . "Se, em 85, vivíamos o sonho pós-moderno multiculturalista, hoje, ao contrário, pensar a diferença é enfrentar um tempo no qual emergem, sem aviso prévio, novos e ferozes racismos, xenofobias radicais, intolerâncias violentas" (HollandA, s.d., s.p.).

Pensar as questões de gênero, agora, deixou de ser mera veleidade pós-moderna para se tornar, mais do que nunca, uma questão político-ideológica da mais alta importância para o desenvolvimento cultural da humanidade.

\section{Referências}

Barcellos, José Carlos. Literatura e homoerotismo em questão. Rio de Janeiro: Dialogarts, 2002. CAlvino, Italo. Seis propostas para o próximo milênio. São Paulo: Companhia das Letras, 2006. Hall, Stuart. A identidade cultural da pós-modernidade. Rio de Janeiro: DPひđA, 2002.

Hollanda, Heloísa Buarque de. Os estudos de gênero e a mágica da globalização. Site da autora. On-line. <http://www.heloisabuarquedehollanda.com.br/os-estudos-de-genero-e-amagica-da-globalizacao/>. Acesso em: 20 fev. 2017. 
Hutcheon, Linda. Narcissistic narrative: the metafictional paradox. Waterloo: Wilfrid Laurier University Press, 1980.

Hutcheon, Linda. Poética do pós-modernismo: história, teoria, ficção. Rio de Janeiro: Imago, 1991.

LAClau, Ernesto. A política e os limites da modernidade. In: Hollanda, Heloísa Buarque de. Pós-modernismo e política. Rio de Janeiro: Rocco, 1992, p. 127-149.

MoRICONI, Ítalo. Literatura moderna e homossexualismo (pressupostos básicos, ou melhor, mínimos). In: Golin, C.; Weiler, L. G. (Org.). Homossexualidade, cultura e política. Porto Alegre: Sulina, 2002, p. 95-109.

SAntiago, Silviano. O falso mentiroso: memórias. Rio de Janeiro: Rocco, 2004.

VAlEntim, Jorge. "Corpo no outro corpo": homoerotismo na narrativa portuguesa contemporânea. São Carlos: EDUfScar, 2016.

Recebido em 23 de fevereiro de 2017.

Aprovado em 22 de abril de 2017. 